\title{
The Role of Prevention and Simple Interceptive Measures in Reducing the Need for Orthodontic Treatment
}

\author{
Heidi Kerosuo \\ Faculty of Dentistry, Kuwait University, Kuwait
}

\author{
Key Words \\ Orthodontics, interceptive - Prevention - Dentition, \\ primary and mixed
}

\begin{abstract}
The purpose of the interceptive orthodontic treatment is to eliminate or reduce the need for treatment in the permanent dentition. The major advantage of such a treatment may also be that it is technically simple and relatively cheap, compared to comprehensive treatment with full fixed appliances. The need for interceptive measures to avoid adverse occlusal and dental consequences, which are effects of the early loss of primary molars and nonnutritive sucking habits, is discussed. The need for prevention and early intervention in patients with anterior open bites, posterior functional crossbites and signs of ectopic erupting canines is also discussed.
\end{abstract}

Copyright $(02002$ S. Karger AG, Basel

\section{Introduction}

Treatment of malocclusion comprises corrective as well as preventive measures. Preventive measures may sometimes be made already in the primary or early mixed dentition, when the first signs of occlusal maldevelop- ment can be recognized. Orthodontic textbooks consider the potential of such early treatment to be rather limited, benefiting only $15-20 \%$ of those needing treatment [1, 2]. This figure reflects mainly the indications for measures to break deleterious, nonnutritive sucking habits and eliminate the adverse effects of the premature loss of deciduous molars.

Early treatment as defined by the College of Diplomates of the American Board of Orthodontics is treatment started in either the primary or mixed dentition to enhance the dental and skeletal development before the establishment of the permanent dentition [3, 4]. Its purpose is to correct or intercept a malocclusion, thereby reducing the need for or the complexity of any treatment in the permanent dentition $[3,4]$. The basic principles of early intervention are to eliminate any primary etiological factors, to manage arch length discrepancies and to correct skeletal dysplasia [5]. The advantages are that such treatment may be technically simple and relatively cheap compared to comprehensive treatment with fixed appliances, and that the scope is within the competency of experienced general dentists [6-8].

In countries where orthodontic treatment has become a part of the public oral health care for children and adolescents, the high frequency of and demand for treatment have generated interest in a more systematically planned application of interceptive measures in orthodontics

\begin{tabular}{ll}
\hline KARGER & ( ) 2002 S. Karger AG, Basel \\
$1011-7571 / 02 / 0115-0016 \$ 18.50 / 0$ \\
$\begin{array}{l}\text { Fax +41613061234 } \\
\begin{array}{l}\text { E-Mail karger@karger.ch } \\
\text { www.karger.com }\end{array}\end{array}$ & $\begin{array}{l}\text { Accessible online at: } \\
\text { www.karger.com/journals/mpp }\end{array}$
\end{tabular}

Heidi Kerosuo
Faculty of Dentistry, Kuwait University
PO Box 24923
Safat 13110 (Kuwait)
Tel. +965 5312300, ext. 6660, Fax +965 5326049, E-Mail heidi.kerosuo@hsc.kuniv.edu.kw 
$[6,7]$. However, few studies exist on the applicability of interceptive orthodontics in the community $[6,9,10]$. In a study from Northern Ireland, 33\% of 9- and 11-year-old children were assessed to benefit from interceptive orthodontics, but only $20 \%$ of those in need followed through with treatment [6]. Among those complying fully, the interceptive measures were successful, and the need for further treatment was significantly reduced [6]. Similarly, a cost and productivity analysis of orthodontic care carried out in Finnish municipal health centers suggested that savings might be obtained by starting treatments early [8].

\section{Arch Length Discrepancies due to Caries}

Preservation of a healthy primary dentition until the time of normal shedding is of the utmost importance for normal eruption of premolars and canines [11]. Loss of interproximal tooth material due to untreated caries of primary molars or premature extractions of these teeth is associated with mesial migration of the permanent molars. The consequence may be a shortening of the dental arch, crowding of the permanent dentition and alteration of the anteroposterior molar relationships [11-15]. The risk may be particularly high if the events occur early, before the eruption of the first permanent molars $[12,14$, 16]. In addition, preexisting crowding may accentuate the potential for space loss $[11,12,16]$. Although a recent study in a 'caries-affected' group of children suggests that mandibular crowding is more frequent than maxillary [15], it is generally accepted that the risk of space loss is highest in the maxillary arch $[12,16]$.

Fluoridation programs, increased use of fluoride toothpastes, increased dental awareness and adequate treatment of carious primary teeth have significantly reduced caries lesions affecting occlusion in the industrialized countries [17-19]. Hence, occlusal discrepancies caused by premature extractions of primary molars are no longer a major problem in the Western world [15, 18]. As an example, only 3 out of 9313 - to 5-year-old Finnish children were judged to need orthodontic intervention or follow-up due to primary molar extractions [20]. However, restorative caries therapy was needed in $12 \%$ of the children [20]. The low number of extractions may partly be due to the young age of the study group. The numbers are not as encouraging in different populations of higher age. Recently, about $25 \%$ of 6 - to 13 -year-old children in Jerusalem exhibited some degree of occlusal mutilation due to caries [15].

The Role of Prevention and Interceptive Measures in Orthodontics
Routine use of space maintainers has been recommended following any early loss of primary molars more than 6 months before the expected eruption of the permanent successors [2]. The space may be maintained with fixed as well as removable appliances. The advantage of fixed designs is that they are less dependent on patient cooperation compared to removable ones [2]. Removable space maintainers have also been suggested to prevent the increase in intercanine arch width and length during the transition period from the primary to the permanent dentition [21].

Early loss of primary molars does not indicate use of space maintainers as a rule, but the need for a space maintainer can be decided individually according to the state of eruption, type of occlusion, general spacing or crowding tendency, oral hygiene status and cooperation of the child [20]. In a recent literature review, Brothwell [22] concluded that there is poor evidence to recommend general guidelines for or against the use of space maintainers. Instead, the above-mentioned clinical guidelines can be used in the decision-making regarding space maintainers in individual patients [22].

\section{Nonnutritive Sucking Habits}

The activity and tension of the cheeks and lips from the outside and the tongue from the inside are important factors, which guide the occlusal development [2]. If the equilibrium among the cheek, the lip muscles and the tongue is interrupted, disturbances in the skeletal and occlusal development may often result. The effect of sucking habits on the occlusion was reported more than a century ago [23], and there is now general agreement regarding the role of sucking habits on the development of malocclusion in the primary dentition $[24,25]$.

According to the 'learned behavior' theory currently in vogue, sucking is an innate urge in infants, and pacifier/ digit-sucking is an outlet for any excess sucking urge produced by today's efficient bottle-feeding [26]. Early introduction of bottle-feeding and short duration of breastfeeding have been associated with pacifier use [27, 28]. Recent ultrasonographic studies suggest that there are striking differences in the orofacial muscle activity of breast-fed and bottle-fed infants [29, 30]. Early weaning has also been suggested to relate with increased posterior crossbite by interfering with normal development of the palate and alveolar ridges [31].

Currently, the majority of children, $55-80 \%$, in the industrialized countries have a history of pacifier-sucking

Med Principles Pract 2002;11(suppl 1):16-21 


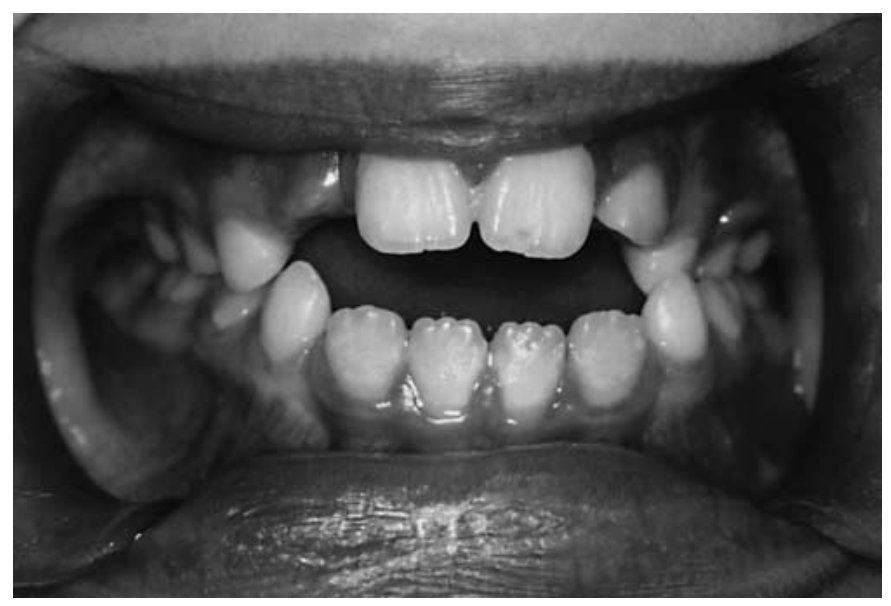

Fig. 1. Anterior open bite and posterior crossbite of primary canine caused by thumb-sucking in a 7-year-old boy.

in early childhood [27, 28, 32-34]. The frequency of the habit decreases rapidly with age, with only $1 \%$ retaining the habit at the age of $6[20,24]$. However, the prevalence varies among cultures. Only $38 \%$ of the Saudi children, aged 3-5 years, have been found to use pacifiers [35], and the habit is very rare among traditional populations in parts of Africa and Asia [26, 28].

Digit-sucking is typically less prevalent in Western countries - 10-25\%, depending on age - due to the increase in pacifier use $[25,28,34]$. However, the habit lasts longer in children with the digit-sucking habit [25]. About half of the children will still stick to the habit at the age of 7, and many of them up to the ages of 9 and 10 [25, 26].

\section{Anterior Open Bite}

Continuing pacifier- or finger-sucking is almost always associated with an anterior open bite (fig. 1), due to a reduction in the vertical growth of the anterior parts of the alveolar processes during sucking [36, 37]. However, even severe open bites will usually correct spontaneously after breaking the habit $[20,24,25]$. Then the alveolar process seems to accelerate in growth and the incisors in both jaws will erupt until incisal contact has been established. In 16year-old children who had been finger suckers until at least the age of 9, lack of incisal contact of the lower incisors was actually less common than that in corresponding children with no previous habit [36]. Different designs in the teat of the pacifier, especially the introduction of a flat design instead of round, have been effective in reducing the severity of the open bite but have not solved the problem of disturbed orofacial muscle activity during pacifiersucking.

Tongue-thrusting during swallowing is almost always associated with an anterior open bite both in pacifier and digit suckers [24, 25, 38]. However, in most cases, this swallowing habit does not appear to be strong enough to prevent the incisors from reaching normal contact within a few years after breaking the sucking habit $[24,38]$. Therefore, any active treatment, if planned, should be postponed for at least 1 or 2 years after discontinuing the sucking habit $[20,24]$.

\section{Posterior Crossbite}

Posterior crossbites are among the most prevalent malocclusions in the primary dentition of Caucasian children, with reported prevalences varying from 9 to $23 \%$ [39-41]. Nonnutritive sucking habits have been considered as important etiological factors for posterior crossbites in the primary dentition $[25,28,32,33,40]$. The consequences of the sucking habit on the occlusion are related to the intensity and duration of the habit [32]. A recent study in Swedish girls under 3 years of age reported that there is a potential to reduce the risk of posterior crossbite in pacifier suckers by asking the parents to reduce the time the pacifier is in the child's mouth [28].

The development of the crossbite in the primary dentition may often be explained by an increased activity of the cheeks combined with a reduced lingual support for the upper primary molars and canines, as the tongue is forced downwards by the teat or the finger. The altered function leads to the narrowing of the maxillary arch, which creates interfering occlusal contacts mainly on the primary canines, resulting in a forced lateral guidance of the mandible and a unilateral posterior crossbite. The vast majority of crossbites in children have been associated with a functionally forced lateral bite [41].

The need for early treatment of posterior crossbites is generally accepted. Posterior crossbites are suggested in many cases to be transferred from the primary to the permanent dentition [41, 42]. Crossbites in the primary dentition affect mandibular function during the period in which the morphology of the temporomandibular joint is being formed. An untreated posterior crossbite has been associated with asymmetric condylar position, which may predispose to progressive compensations in the temporomandibular area resulting in craniofacial asymmetry and increased risk of temporomandibular disorders [43-46]. 
As the predictability of such a development is rather limited, the importance of early treatment is frequently stressed [39, 41, 44, 46, 47].

Selective grinding in the primary dentition may successfully remove occlusal interferences, thereby eliminating a functional posterior crossbite and preventing transfer of the condition to the permanent dentition [41, 47]. Spontaneous correction has also been noticed in $8-45 \%$ of untreated cases, which may reflect the fact that crossbites are often secondary to sucking habits [41]. If the habit is not prolonged, the transverse relations may have the capacity to normalize due to favorable change in function. Therefore, for purposes of cost-effectiveness, in those children maxillary expansion treatment for correction of posterior crossbites may be postponed to the early mixed dentition [39, 41].

\section{Impaction of the Maxillary Canines}

The maxillary canines normally develop apically to their adjacent teeth and therefore have a long path of eruption. They also complete their development late compared to their neighboring teeth $[48,49]$. For these reasons, eruption disturbances are more frequent in maxillary canines than in any other teeth, except third molars, with a population prevalence of about $2 \%$ [48-50]. In most cases, the impacted canine is situated palatal to the dental arch; only about $15 \%$ of the impactions occur buccally [51]. A palatal position of the canine and crowding in the canine region have been suggested to be the most important local risk factors for impaction of the maxillary canines [48].

An ectopic eruption pattern of the upper canine always includes a risk for impaction or resorption of the adjacent teeth. Therefore, early diagnosis and supervision of eruption disturbances have increasingly been emphasized to reduce the number and severity of any complications and the need for consequent orthodontic treatment [49, 52]. Both clinical and radiographic methods have been used to diagnose the canine position in the developing dentition $[49,52]$. Clinically, a bulge of the alveolar process should be palpable in the buccal sulcus above the primary canine at about 10 years of age $[49,52]$. The absence of a bulge, particularly asymmetrically, may indicate an abnormal eruption path of the canine. Digital palpation methods have been recommended as a routine for early screening of palatal canines. In cases of a negative palpation result, a radiographic examination should follow, as confirmation of the diagnosis is required $[49,52]$.

The Role of Prevention and Interceptive Measures in Orthodontics
The common treatment concept for palatal canines in children and adolescents has been surgical exposure of the ectopic canine followed by treatment mainly with fixed appliances [53, 54]. However, early extractions of the primary canines have been reported to have a favorable effect on the eruption path of ectopically positioned canines provided eruption space is available [49, 52]. Indeed, $78 \%$ of 10 - to 13 -year-old children were found to exhibit a change from palatal to normal position following primary canine extractions [52]. The results of these interceptive extractions seem to be particularly effective if the ectopic eruption path is identified before the age of 11 and the changes in the position of the canine are observed within 12 months of the extraction [49, 52]. It seems that the present evidence supports early diagnosis with intervention in patients with ectopically positioned canines.

\section{Early versus Late Treatment}

Regarding malocclusions and conditions other than those discussed above, there is no general agreement about the effectiveness of early intervention [4]. Particularly, the potential for extended total treatment time has been considered as a possible disadvantage of early treatment. The results from recent clinical studies on correction of distal occlusions have not supported the advantages of early treatment as opposed to treatment started in the early permanent dentition $[55,56]$. The exception is patients who need overjet reduction and establishment of lip competency to reduce the risk of traumatic injuries to the protruding incisors $[57,58]$. In skeletal class III patients, for whom early intervention has been widely recommended and short-term results were reported favorable [55, 59-61], the long-term effects have been difficult to predict and the risk for relapse and the possibility for orthognathic surgery must be considered in each individual patient [62]. The present scientific evidence may not be sufficient to offer clear guidelines for the clinician regarding the timing of orthodontic treatment. In many conditions, the advantages and limitations of early intervention must be considered individually for each patient, without omitting psychological factors such as patient cooperation and self-esteem in the decision-making.

New perspectives on orthodontic prevention have also been presented [63]. Some recent twin and sibling studies have revealed that the role of genetic factors in the etiology of malocclusion may not be as decisive as previously thought. This indicates that a major portion of the occlusal variation may be environmentally regulated, and ow-

Med Principles Pract 2002;11(suppl 1):16-2 
ing to that many of the malocclusions may be acquired rather than inherited [63-65]. The genetic determination of the maxillary components has been found low compared to the genetic control of the mandible, and components and units with a lower genetic determination are more open to interceptive or orthodontic measures than those with a high genetic determination [66, 67]. This may warrant new approaches for the prevention and early intervention of deviations related to the maxillary complex. Research programs examining the value of prevention and early treatment are needed to find potential new alternatives for the traditional orthodontic treatment in the future.

\section{Conclusion}

Attempts at prevention and early orthodontic intervention are generally successful in minimizing the detrimental dental and occlusal effects of nonnutritive sucking habits and early loss of primary molars. Interception and early treatment of functional posterior crossbites and signs of ectopic canine eruption have been equally successful. In such cases, the potential for a complete cure or significant reduction of the need for orthodontic treatment in the permanent dentition is well documented.

\section{References}

1 Graber TM, Swain BF: Orthodontics: Current Principles and Techniques. St Louis, Mosby, 1985.

2 Proffit WR (ed): Contemporary Orthodontics. St Louis, Mosby Year Book, 1993.

3 Bishara SE, Justus R, Graber TM: Proceedings of the workshop discussions held on early treatment. Am J Orthod Dentofac Orthop 1998; 113:5-6.

4 White L: Early orthodontic intervention. Am J Orthod Dentofac Orthop 1998;113:24-28.

5 Arvystas M: The rationale for early treatment. Am J Orthod Dentofac Orthop 1998;113:1518.

6 Al Nimri K, Richardson A: Interceptive orthodontics in the real world of community dentistry. Int J Pediatr Dent 2000;10:99-108.

7 Pietilä T: Orthodontic Care in Finnish Health Centers; thesis. University of Turku, 1998.

8 Pietilä T, Sintonen H, Pietilä I, Widström E, Varrela J, Alanen P: Cost and productivity analysis of orthodontic care in Finland. Community Dent Oral Epidemiol 1998;26:283288.

9 Al Nimri A: Applicability of interceptive orthodontics in the community. Br J Orthod 1997; 24:223-228.

10 Pulkkinen E, Pulli H: Oikomishoito Kajaanin terveyskeskuksessa. Suomen Hammaslääkäril 1991;38:802-805.

11 Leighton BC: Longitudinal study of features which might influence space loss after early extraction of lower deciduous molars. Proc Finn Dent Soc 1981;77:95-103.

12 Lundström A: The significance of early loss of deciduous teeth in the etiology of malocclusions. Am J Orthod 1955;41:819-826.

13 Pedersen J, Stensgaard K, Melsen B: Prevalence of malocclusion in relation to premature loss of primary teeth. Community Dent Oral Epidemiol 1978;6:204-209.
14 Rönnerman A: The effect of early loss of primary molars on tooth eruption and space conditions: A longitudinal study. Acta Odontol Scand 1977;35:229-239.

15 Ben-Bassat Y, Harari D, Brin I: Occlusal traits in a group of school children in an isolated society in Jerusalem. Br J Orthod 1997;24:229_ 235.

16 Rönnerman A, Thilander B: Facial and dental arch morphology in children with and without early loss of deciduous molars. Am J Orthod 1978;73:47-58.

17 Stecksen-Blicks C, Holm AK: Dental caries, tooth trauma, malocclusion, fluoride usage, toothbrushing and dietary habits in 4-year-old Swedish children: Changes between 1967 and 1992. Int J Paediatr Dent 1995;5:143-148.

18 Brin I, Zwilling-Sellam O, Harari D, Koyoumdjisky-Kaye E, Ben-Bassat Y: Does a secular trend exist in the distribution of occlusal patterns? Angle Orthod 1998;68:81-84.

19 Murray JJ: The changing pattern of dental disease; in Murray JJ (ed): Prevention of Oral Disease. Oxford, Oxford University Press, 1996, pp 250-274.

20 Järvinen S: Need for preventive and interceptive intervention for malocclusion in 3- to 5year-old Finnish children. Community Dent Oral Epidemiol 1981;9:1-4.

21 Dincer M, Haydar S, Unsal B, Turk T: Space maintainer effects on intercanine arch width and length. J Clin Pediatr Dent 1996;21:4750.

22 Brothwell DJ: Guidelines on the use of space maintainers following premature loss of primary teeth. J Can Dent Assoc 1997;63:753-766.

23 Chandler TH: Thumb-sucking in childhood as a cause of subsequent irregularity of the teeth. Dent Cosmos 1878;20:565-570.

24 Larsson E: The effect of dummy-sucking on the occlusion: A review. Eur J Orthod 1986;8:127130.

25 Larsson E: The effect of finger-sucking on the occlusion: A review. Eur J Orthod 1987;9:279282.
26 Levine RS: Briefing paper: Oral aspects of dummy and digit sucking. Br Dent J 1998;186: 108.

27 Victora CG, Tomasi E, Olinto MTA, Barros FC: Use of pacifiers and breastfeeding duration. Lancet 1993;341:404-406.

28 Larsson E: Sucking, chewing and feeding habits and the development of crossbite: A longitudinal study of girls from birth to 3 years of age. Angle Orthod 2001;71:116-119.

29 Weber F, Woolridge MW, Baum JD: An ultrasonographic study of the organization of sucking and swallowing by newborn infants. Dev Med Child Neurol 1986;28:19-24.

30 Nowak AJ, Smith WL, Erenberg A: Imaging evaluation of artificial nipples during bottle feeding. Arch Pediatr Adolesc Med 1994;148: 40-42.

31 Karjalainen S, Rönning O, Lapinleimu H, Simell O: Association between early weaning, non-nutritive sucking habits and occlusal anomalies in 3-year-old Finnish children. Int $\mathrm{J}$ Paediatr Dent 1999;9:169-173.

32 Lindner A, Modeer T: Relation between sucking habits and dental characteristics in preschoolchildren with unilateral cross-bite. Scand J Dent Res 1989;97:278-283.

33 Adair SM, Milano M, Lorenzo I, Russel C: Effects of current and former pacifier use on the dentition of 24- to 59-month-old children. Pediatr Dent 1995; 17:437-444.

34 Warren JJ, Levy SM, Nowak AJ, Tang S: Nonnutritive sucking behaviors in preschool children: A longitudinal study. Pediatr Dent 2000; 22:187-191.

35 Farsi NM, Salama FS: Sucking habits in Saudi children: Prevalence, contributing factors and effects on the primary dentition. Pediatr Dent 1997;19:28-33. 
36 Larsson E: Dummy- and finger-sucking habits with special attention to their significance for facial growth and occlusion. 7. The effect of earlier dummy- and finger-sucking in 16-yearold children compared with children without earlier sucking habit. Swed Dent J 1978;1:2333.

37 Larsson E, Rönnerman A: Clinical crown length in 9-, 11- and 13-year-old children with and without finger-sucking habit. Br J Orthod 1981;8:171-173.

38 Melsen B, Stensgaard K, Pedersen J: Sucking habits and their influence on swallowing pattern and prevalence of malocclusion. Eur $\mathrm{J}$ Orthod 1979; 1:271-280.

39 Hannuksela A, Laurin A, Lehmus V, Kouri R: Treatment of cross-bite in early mixed dentition. Proc Finn Dent Soc 1988;88:175-182.

40 Kerosuo H: Occlusion in the primary and early mixed dentition in a group of Tanzanian and Finnish children. J Dent Child 1990;57:293298.

41 Kurol J, Berglund L: Longitudinal study and cost-benefit analysis of the effect of early treatment of posterior cross-bites in the primary dentition. Eur J Orthod 1992;14:173-179.

42 Helm S: Prevalence of malocclusion in relation to development of the dentition: An epidemiological study of Danish schoolchildren. Acta Odontol Scand 1970;28(suppl 58):1+.

43 Egermark-Eriksson I, Carlsson GE, Magnusson $\mathrm{T}$, Thilander B: A longitudinal study on malocclusion in relation to signs and symptoms of cranio-mandibular disorders in children and adolescents. Eur J Orthod 1990;12:399-407.

44 Pirttiniemi P, Kantomaa T, Lahtela P: Relationship between craniofacial and condyle path asymmetry in unilateral cross-bite patients. Eur J Orthod 1990;12:408-413.

45 O'Byrn B, Sadowsky C, Schneider B, BeGole E: An evaluation of mandibular asymmetry in adults with unilateral crossbite. Am J Orthod Dentofac Orthop 1995;107:394-400.
46 Hesse KL, Årtun J, Joondeph DR, Kennedy DB: Changes in condylar position and occlusion associated with maxillary expansion for correction of functional unilateral crossbite. Am J Orthod Dentofac Orthop 1997;111:410418.

47 Harrison JE, Ashby D: Orthodontic treatment for posterior crossbites. Cochrane Database of Systematic Reviews [computer file]. (2): CD000979, 2000.

48 Thilander B, Jacobsson SO: Local factors in impaction of maxillary canines. Acta Odontol Scand 1968;26:145-168.

49 Williams BH: Diagnosis and prevention of maxillary cuspid impaction. Angle Orthod 1981;51:30-40.

50 Ericson S, Kurol J: Radiographic assessment of maxillary canine eruption in children with clinical signs of eruption disturbance. Eur J Orthod 1986;8:133-140.

51 Ericson S, Kurol J: Radiographic examination of ectopically erupting maxillary canines. Am J Orthod Dentofac Orthop 1987;91:483-492.

52 Ericson S, Kurol J: Early treatment of palatally erupting maxillary canines by extraction of the primary molars. Eur J Orthod 1988;10:283295.

53 Bishara SE, Kommer DD, McNeil MH, Montegano LN, Oesterle LJ, Youngquist HW: Management of impacted canines. Am J Orthod 1976;69:371-387.

54 Hunter SB: Treatment of the unerupted maxillary canine. I. Preliminary considerations and surgical methods. Br Dent J 1983;154:294296.

55 Gianelly A: One-phase versus two-phase treatment. Am J Orthod Dentofac Orthop 1995; 108:556-559.

56 Tulloch JFC, Phillips C, Proffit WR: Benefit of early class II treatment: Progress report of a two-phase randomized clinical trial. Am J Orthod Dentofac Orthop 1998;113:62-72.
57 Järvinen S: Incisal overjet and traumatic injuries to upper permanent incisors. Acta Odontol Scand 1978;36:359-362.

58 Dearing SG: Overbite, overjet, lip-drape and incisor tooth fracture in children: NZ Dent J 1984;80:50-52.

59 McNamara JA: An orthopedic approach to the treatment of class III malocclusions in young patients. J Clin Orthod 1987;21:598-608.

60 Takada K, Petdachai S, Sakuda M: Changes in dentofacial morphology in skeletal class III children treated by a modified maxillary protraction headgear and a chin cap: A longitudinal cephalometric appraisal. Eur J Orthod 1993; 15:211-221.

61 Chong Y-H, Ive JC, Årtun J: Changes following the use of protraction headgear for early correction of class III malocclusion. Angle Orthod 1996;66:351-362.

62 Campbell PM: The dilemma of class III treatment. Early or late? Angle Orthod 1983;53: 175-191.

63 Varrela J, Alanen P: Prevention and early treatment in orthodontics: A perspective. J Dent Res 1995;74:1436-1438.

64 Townsend GC, Corruccini RS, Richards LC, Brown T: Genetic and environmental determinants of dental occlusal variation in South Australian twins. Aust Orthod J 1988;10:231-235.

65 Harris EF, Johnson MG: Heritability of craniometric and occlusal variables: A longitudinal sib analysis. Am J Orthod Dentofac Orthop 1991;99:259-268.

66 Lunström A, McWilliam JS: Comparison of some cephalometric distances and corresponding facial proportions with regard to heritability. Eur J Orthod 1988;10:27-29.

67 Savoye I, Loos R, Carels C, Derom C, Vlietinck $\mathrm{R}$ : A genetic study of anteroposterior and vertical facial proportions using model-fitting. Angle Orthod 1998;68:467-470. 